\title{
Susceptibilidade antibiótica de isolados bacterianos em diferentes tipos de ceratites ulcerativas de cães na cidade de Cuiabá ${ }^{1}$
}

\author{
Geovanna B. Monteiro², Thaís Ruiz², Deise C. Schroder², \\ Marcelo M. Silveira ${ }^{2}$, Nathalie M.B. Dower ${ }^{2}$, Francielle Kagueyama ${ }^{2}$, \\ Valéria Dutra $^{3}$ e Alexandre P. Ribeiro ${ }^{3 *}$
}

\begin{abstract}
ABSTRAT.- Monteiro G.B., Ruiz T., Schroder D.C., Silveira M.M., Dower N.M.B., Kagueyama F., Dutra V. \& Ribeiro A.P. 2018. [Antibiotic susceptibility of bacteria isolated from different types of ulcerative keratitis of dogs in the city of Cuiabá, Brazil.] Susceptibilidade antibiótica de isolados bacterianos em diferentes tipos de ceratites ulcerativas de cães na cidade de Cuiabá. Pesquisa Veterinária Brasileira 38(4):726-733. Faculdade de Medicina Veterinária, Universidade Federal de Mato Grosso, Av. Fernando Corrêa da Costa 2367, Boa Esperança, Cuiabá, MT 78060-900, Brazil. E-mail: alexandre.aleribs@gmail.com

The purpose of the present study was to analyze antibiotic susceptibility of bacteria associated with different types of ulcerative keratitis in dogs. The outcome of medical or surgical treatment was also correlated with the type of isolate. Samples for microbiology were obtained by means of sterile swab from 104 eyes of 72 canine patients with ulcerative keratitis without previous history of antibiotic treatment, seen from May 2012 to March 2015. Only patients with no previous treatment with antibiotics were included in the study. Bacterial isolates were identified and the antibiotic susceptibility was tested to neomycin, gentamicin, tobramycin, chloramphenicol, polymyxin B, ciprofloxacin, ofloxacin and moxifloxacin. In total, 131 species of bacteria were isolated from 96/104 eyes, and Staphylococcus sp. predominated (48.09\%), followed by Pseudomonas aeruginosa (16.01\%). Shih Tzus were over represented (33.33\%) and the number of gram-negative isolates were significantly higher in this breed, in comparison to Pinchers $(P=0.003)$, Filas, Poodles, and other mixed-breeds $(P=0.046)$. All species isolated in this study were more sensitive to ofloxacin (84.55\%), that was significantly most efficient than neomycin and polymyxin B $(P<0.0001)$, chloramphenicol $(P=0.0001)$, tobramycin $(P=0.0007)$, gentamicin $(P=0.0021)$ and the other fluoroquinolones, ciprofloxacin $(P=0.0004)$ and moxifloxacin $(P<0.0001)$. Gram-positive organisms were isolated in a significant larger number of eyes with uncomplicated ulcerative keratitis, in comparison to those eyes with complicated ulcerative keratitis $(P=0.011)$. Likewise, gram-positive were isolated in a larger number than gram-negatives microorganisms in cases that received either medically or surgical treatment, without statistical significance $(P=0.745)$. In the present research, Staphylococcus sp. was the bacteria most commonly isolated in the eyes with uncomplicated ulcerative keratitis. Although Pseudomonas aeruginosa was the most common isolate in the eyes with complicated ulcerative keratitis, the majority of cases managed clinically had a successful outcome. Ofloxacin and gentamicin were found to be effective against the majority of isolates, with the exception of Streptococcus. sp, in which chloramphenicol was the most effective antibiotic. Uncomplicated ulcerative keratitis presenting negative culture may evolve to complicated ulcerative keratitis, warring the necessity of anti-collagenolytic treatment in all cases.
\end{abstract}

INDEX TERMS: Antibiotic susceptibility, ulcerative keratite, dogs, microorganisms, prevalence, pets, bacterioses.

\footnotetext{
${ }^{1}$ Recebido em 3 de marco de 2017.

Aceito para publicação em 21 de março de 2017.

${ }^{2}$ Pós-graduandos em Ciências Veterinárias, Faculdade de Medicina Veterinária, (FAVET), Universidade Federal de Mato Grosso (UFMT), Av. Fernando Corrêa da Costa 2367, Boa Esperança, Cuiabá, MT 78060-900, Brasil.

${ }^{3}$ Docente da Faculdade de Medicina Veterinária (FAVET), Universidade Federal de Mato Grosso (UFMT), Av. Fernando Corrêa da Costa 2367, Boa Esperança, Cuiabá, MT 78060-900. *Autor para correspondência: alexandrealeribs@gmail.com
}

RESUMO.- Objetivou-se identificar microrganismos isolados de diferentes tipos de ceratite ulcerativa em cães, juntamente com a sua susceptibilidade a antimicrobianos. 0 resultado do tratamento médico e cirúrgico também foi correlacionado com o tipo de isolado. Amostras para microbiologia foram obtidas com auxílio de swab estéril em 104 olhos de 72 pacientes 
sem histórico prévio de tratamento com antibióticos tópicos, atendidos no período de maio de 2012 a março de 2015. Os antibióticos testados foram: neomicina, gentamicina, tobramicina, cloranfenicol, polimixina B, ciprofloxacino, ofloxacino e moxifloxacina. No total, 131 bactérias foram isoladas de 96/104 olhos estudados, sendo o gênero Staphylococcus $(48,09 \%)$ predominante, seguido por Pseudomonas aeruginosa $(16,01 \%)$. O Shih Tzu foi a raça mais prevalente $(33,33 \%)$ e o número de isolados gram-negativos foi significativamente maior nessa raça, comparativamente aos Pinschers $(p=0,003)$, aos Filas, aos Poodles e aos sem raça definida $(p=0,046)$. As bactérias isoladas neste estudo apresentaram maior susceptibilidade ao ofloxacino $(84,55 \%)$, que foi significativamente mais eficaz em relação a neomicina e a polimixina $B(p<0,0001)$, ao cloranfenicol ( $p=0,0001)$, a tobramicina $(p=0,0007)$, a gentamicina $(p=0,0021)$ e as outras fluorquinolonas, ciprofloxacino $(\mathrm{p}=0,0004)$ e moxifloxacino $(\mathrm{p}<0,0001)$. Os organismos gram-positivos foram isolados de um número significativamente maior de olhos que apresentavam ceratite ulcerativa não complicada, comparativamente àqueles com olhos acometidos por ceratite ulcerativa complicada $(\mathrm{p}=0,011)$. Igualmente, o número de bactérias gram-positivas foi maior que o de gram-negativas, tanto nos casos que receberam tratamento médico, como nos que foram operados, sem significativa estatística $(p=0,745)$. Na presente pesquisa, Staphylococcus sp. foi a bactéria mais encontrada nas ceratites ulcerativas não complicadas. Já nos olhos com ceratites complicadas, embora a Pseudomonas aeruginosa tenha sido a bactéria mais predominante, o tratamento clínico foi suficiente para cura da afecção corneal na maior parte dos casos. 0 ofloxacino e a gentamicina foram os agentes mais eficazes contra a maioria dos isolados, com exceção do Streptococcus sp., onde o cloranfenicol se mostrou o mais eficaz. Ceratites ulcerativas sem complicações que apresentem culturas negativas podem evoluir para ceratites ulcerativas complicadas, salientando a necessidade de tratamento anti-colagenolítico em todos os casos.

TERMOS DE INDEXAÇÃO: Susceptibilidade antibiótica, isolados bacterianos, ceratite ulcerativa, caninos, resistência microbiana, bacterioses.

\section{INTRODUÇÃO}

A ceratite ulcerativa é uma afecção oftálmica de grande frequência em animais de pequeno porte (Galera et al. 2009). A lesão resulta em perda do epitélio corneal, com exposição de porções variáveis do estroma (Galera et al. 2009). A perda de integridade epitelial enseja edema estromal, migração de células inflamatórias e ativação de enzimas líticas (metaloproteinases da matriz, MMPs) (Ribeiro 2015). Quando a inflamação e a proliferação de microrganismos ocorrerem de forma exacerbada, desequilibrando o balanço entre MMPs e seus fatores inibitórios, favorecendo as MMPs, as ceratites ulcerativas podem se aprofundar no estroma de forma focal ou difusa, ensejando o quadro de malácia corneal. Casos mais graves evoluem para perfuração corneal, com prolapso de íris e perda do bulbo ocular (Galera et al. 2009, Ribeiro 2015). A afecção é favorecida em cães braquicefálicos e naqueles acometidos por doenças metabólicas, ceratoconjuntivite seca, uso prévio de corticosteróides e anormalidades dos cílios e das pálpebras (Tolar et al. 2006, Hindley et al. 2016).
Admite-se que microrganismos da microbiota bacteriana ocular findam por contaminar porções da córnea acometidas por ulceração (Galera et al. 2009, Ribeiro 2015). Os agentes bacterianos mais frequentemente isolados da microbiota ocular em cães acometidos por ceratite ulcerativa são Staphylococcus sp., Streptococcus sp., Pseudomonas aeruginosa (P. aeuruginosa), Escherichia coli, Corynebacterium sp. e Bacillus cereus (Hamor 2001, Prado et al. 2005, Tolar et al. 2006, Lin \& Petersen-Jones 2007, Wang et al. 2008, Hindley et al. 2016).

A despeito da necessidade de correção cirúrgica, o tratamento clínico das ceratites ulcerativas é realizado por via tópica e consiste basicamente na instilação de antibióticos, inibidores de MMPs, cicloplégicos e midriáticos, anti-inflamatórios e sucedâneos da lágrima (Ribeiro 2015). Assume-se que a primeira escolha por antibióticos utilizados em ceratites ulcerativas baseia-se naqueles com amplo espectro de ação e com baixa epiteliotoxicidade (Ribeiro 2015). Em todos os casos, indica-se a utilização de antibióticos efetivos contra $P$. aeruginosa devido ao seu potencial em aprofundar-se no epitélio corneal, impedindo que células de defesa do hospedeiro atinjam o sítio infeccionado (Ledbetter et al. 2009). Ademais, reconhece-se o seu potencial em produzir MMPs, que podem prolongar a digestão do colágeno corneal por até 12 horas, decorrido o início com tratamento antibiótico (Ikema et al. 2006). Com base em cultura e antibiograma, antibióticos específicos podem ser recomendados. Em humanos com ceratite ulcerativa reportou-se que o ciprofloxacino e a gentamicina apresentaram maior eficácia contra P. aeruginosa, quando comparados à amicacina e a tobramicina (Lalitha et al. 2005). 0 ciprofloxacino também se mostrou mais eficaz que outros antibióticos contra esse agente, em cães com ceratite ulcerativa em Taiwan (Lin \& Petersen-Jones, 2007), nos Estados Unidos (Ledbetter et al. 2007), na China (Wang et al. 2008), na Austrália (Hindley et al. 2016) e na Inglaterra (Everson et al. 2016). Todavia, estudo conduzido em células epiteliais corneais de cães, demonstrou que o ciprofloxacino e a gentamicina são mais epiteliotóxicos que a tobramicina e o cloranfenicol (Hendrix et al. 2001).

Estudos desenvolvidos nas regiões sudeste (Andrade et al. 2002) e centro-oeste (Santos et al. 2009) do Brasil avaliarem a microbiota ocular de cães sadios e com afecções oculares diversas. Apenas um estudo brasileiro, desenvolvido no Nordeste (Ceará), considerou avaliar a incidência de diferentes bactérias isoladas de ceratites ulcerativas de cães (Prado et al. 2005). A maioria das pesquisas desenvolvidas em diferentes partes do mundo, geralmente apenas classificam as diferentes bactérias isoladas em ceratites ulcerativas e avaliam sua susceptibilidade frente a diferentes antibióticos (Tolar et al. 2006, Ledbetter et al. 2007, Lin \& Petersen-Jones 2007, Wang et al. 2008). Um único estudo desenvolvido em cães da Austrália considerou avaliar o impacto de diferentes agentes bacterianos sobre os aspectos clínicos de ceratites ulcerativas em diferentes estágios (Hindley et al. 2016). Desconhecem-se, até o momento, estudos desenvolvidos no Brasil com esse propósito. Ademais, admite-se a importância do presente estudo, haja vista que a susceptibilidade bacteriana a antibióticos distintos pode diferir ao longo dos anos (Tolar et al. 2006) e em diferentes locais do mundo (Prado et al. 2005, Wang et al. 2008, Hindley et al. 2016). Frente ao exposto, objetivou-se avaliar a susceptibilidade de bactérias isoladas em ceratites ulcerativas sem complicação e com complicações, a diferentes 
agentes antibióticos, e as possíveis correlações entre o tipo de bactéria isolada e o grau de comprometimento corneal, em cães na cidade Cuiabá, Brasil.

\section{MATERIAL E MÉTODOS}

Entre o período de maio de 2012 a março de 2015, cães e cadelas atendidos no setor de Oftalmologia Veterinária do Hospital Veterinário da Universidade Federal de Mato Grosso (UFMT) foram oftalmicamente avaliados, empregando-se o Teste da lágrima de Shirmer, a biomicroscopia com lâmpada em fenda, a tonometria de aplanação, a oftalmoscopia binocular indireta e o teste de tingimento com a fluoresceína. Todos os pacientes sem tratamento prévio com antibióticos e com impregnação de fluoresceína na córnea foram incluídos no estudo. Estabelecido o diagnóstico de ceratite ulcerativa, swab estéril foi esfregado diretamente sobre a região central e periférica da córnea lesionada, transferido para tubo específico para posterior isolamento e identificação de bactérias aeróbicas, seguida pela avaliação da susceptibilidade microbiana. Os protocolos adotados foram aprovados pela Comissão de Ética no Uso de Animais da Universidade Federal de Mato Grosso, Protocolo número 23108.005382/13-6.

As ceratites ulcerativas foram classificadas em: não complicadas (superficiais) (Fig.1A) e complicadas (úlceras indolentes, profundas, com exposição ou prolapso da membrana de Descemet e com perfuração corneal) (Fig.1B-G). Na maior parte dos casos, as ceratites complicadas foram tratadas por ceratotomia em grade mais recobrimento com membrana nictitante (úlceras indolentes), recobrimento total de conjuntiva bulbar (úlceras profundas) e enxerto pediculado da conjuntiva bulbar (casos com exposição ou prolapso da membrana de Descement e com perfuração corneal), conforme recomendado pela literatura veterinária (Gelatt \& Brooks 2011). Em todos os casos, as ceratites ulcerativas (com e sem complicação) foram tratadas com instilações de antibióticos (tobramicina 0,3\% ou cloranfenicol 0,4\%), agentes inibidores de metaloproteinases (EDTA 0,2\% e soro fetal bovino comercial), atropina $1 \%$ e antinflamatórios não esteroidais (cetorolaco trometamol 0,5\% ou diclofenaco sódico 0,1\%).

As amostras encaminhadas ao laboratório em tubos com caldo infusão de cérebro e coração (BHI), prosseguiram semeadas em Ágar Sangue Ovino 5\% e Ágar MacConkey, foram incubadas em ar ambiente a $37^{\circ} \mathrm{C}$, por $24-72$ horas e examinadas diariamente para provas do crescimento microbiano. As placas que não apresentaram crescimento dentro do período de incubação (24-72 horas) foram consideradas resultados negativos. Os isolados foram identificados de acordo com suas características tintoriais, morfológicas e bioquímicas como descrito por Quinn et al. (1994). Os antibióticos testados, pelo método de difusão em disco, foram os aminoglicosídeos, gentacimina, neomicina e tobramicina; o anfenicol, cloranfenicol; o polipeptídeo, polimixina B; e as fluoroquinolonas ciprofloxacino, ofloxacino e moxifloxacina. A escolha dos agentes antibacterianos decorreu da sua ocorrência nas formulações comerciais comumente prescritas na prevenção e no tratamento de afecções oculares.

A susceptibilidade antibiótica da bactéria de maior frequência foi comparada com a susceptibilidade das demais bactérias. Avaliou-se o efeito da raça com relação ao tipo de ceratite ulcerativa (complicada e não complicada) e ao tipo de parede celular do agente isolado (Gram-positivo e Gram-negativo). Ademais, foi avaliado se a característica da parede celular do agente isolado (Gram-positivo e Gram-negativo) exerceu impacto sobre a classificação das ceratites ulcerativas (complicada e não complicada). Utilizou-se o teste Chi-quadrado ou o teste exato de Fisher, se uma das células da tabela
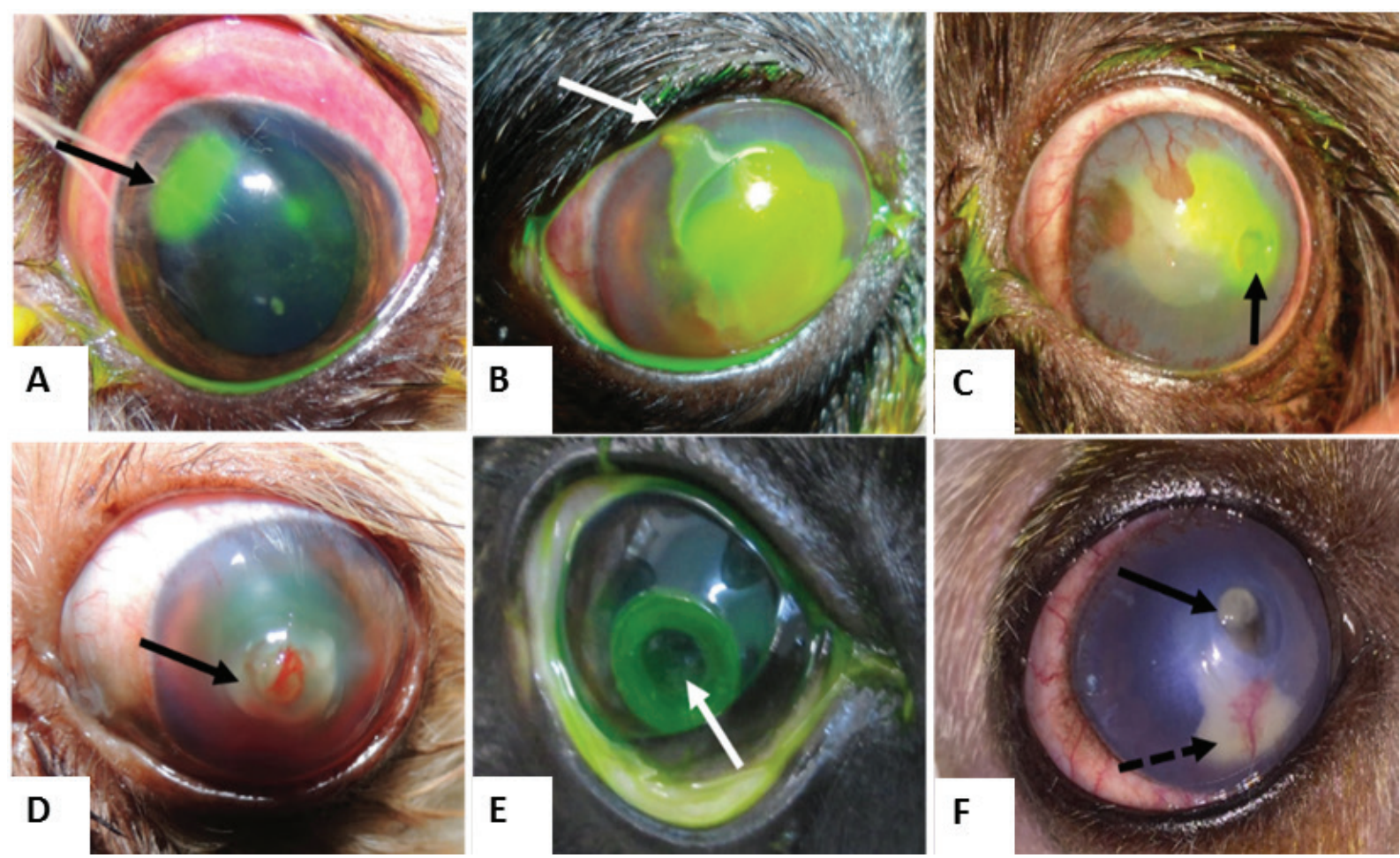

Fig.1. Olhos de cães acometidos por ceratites ulcerativas não complicados e complicados. (A) Cão com ceratite ulcerativa superficial (não complicada) de onde foi isolado Escherichia coli. (B-F) Cães com ceratites complicadas: (B) epitélio solto em um olho apresentando ceratite indolente (seta) de onde foi cultivado Bacillus sp., (C) ceratite profunda (seta), de onde foi isolado Streptococcus sp., (D) ceratite com colagenólise do estroma de onde foi isolado Staphylococcus sp., (E) ceratite com exposição da membrana de Descemet (seta), de onde foi isolado Pseudomonas aeruginosa e (F) observa-se perfuração corneal tamponada de onde foi isolado Enterobacter sp. 
( $4 \times 4)$, apresentasse valores inferiores a cinco. Em todas as análises, valores de $\mathrm{p}<0,05$ foram considerados significativos.

\section{RESULTADOS}

No período avaliado, foram atendidos 194 cães no setor de Oftalmologia do Hospital Veterinário da UFMT com diferentes tipos de ceratite ulcerativas. Desse contingente, 72 cães não apresentavam tratamento prévio com antibióticos e foram introduzidos na pesquisa. A faixa etária acima de seis anos e os machos obtiveram uma frequência maior nesse estudo. As raças mais representadas foram o Shih Tzu $(33,33 \%)$ e os sem raça definida $(27,77 \%)$ (Quadro 1). Cento e quatro olhos de 72 cães apresentavam ceratite ulcerativa de diferentes tipos. Desses, 51 apresentavam ceratite ulcerativa acometendo o olho direito e 53, olho esquerdo. Desse contingente, 81 olhos apresentaram ceratites ulcerativas não complicadas (superficial) e 23 olhos apresentaram ceratites complicadas (Quadro 2).

Amostras positivas foram isoladas em 96/104 (92,30\%) olhos avaliados e culturas negativas compreenderam 8/104 (7,69\%).
Das 131 bactérias isoladas, Staphylococcus predominou em 48,09\% dos casos, seguido por Pseudomonas aeruginosa $(16,01 \%)$, Bacillus $(9,92 \%)$, Enterobacter $(9,16 \%)$, Streptococcus $(6,87 \%)$ e Escherichia coli (5,34\%). 0 isolamento de bactérias Gram-positivas (85/131; 64,89\%) foi mais frequente que o das Gram-negativas (46/131; 35,12\%). Observou-se que o número de isolados Gram-negativos foi significativamente maior nos Shih Tzus, comparativamente ao Pinscher $(\mathrm{p}=0,003)$, ao Fila, ao Poodle e aos sem raça definida $(\mathrm{p}=0,046)$.

Das 131 bactérias isoladas nos diferentes tipos de ceratites ulcerativas incluídos no estudo, 87 bactérias foram provenientes de ceratites ulcerativas não complicadas (superficiais) e 44 bactérias foram isoladas de ceratites ulcerativas complicadas (profunda, indolente, Descementocele e perfurações) (Quadro 2). Não foram obtidas culturas positivas em $4 / 81$ (4,93\%) olhos com úlceras não complicadas e em $4 / 23(17,39 \%)$ olhos com úlceras complicadas. Observouse que o número de isolados do tipo Gram-positivo foi

Quadro 1. Aspectos gerais quanto à presença ou ausência de bactérias em olhos de diferentes raças de cães com ceratite ulcerativa (2012-2015)

\begin{tabular}{|c|c|c|c|c|c|c|}
\hline \multirow{2}{*}{$\frac{\text { Raça }}{\text { (indivíduos) }}$} & \multirow{2}{*}{$\begin{array}{c}\text { № de olhos com } \\
\text { ceratite }\end{array}$} & \multicolumn{2}{|c|}{ Cultura bacteriana } & \multicolumn{2}{|c|}{ Sexo } & \multirow{2}{*}{$\frac{\text { Idade }}{\text { (média em meses) }}$} \\
\hline & & Positiva & Negativa & Macho & Fêmea & \\
\hline Cocker (3) & 4 & 3 & - & 1 & 2 & 96 \\
\hline Dálmata (1) & 2 & 1 & - & 1 & 0 & 12 \\
\hline Dog Alemão (1) & 1 & 1 & - & 1 & 0 & 96 \\
\hline Fila (2) & 3 & 2 & - & 1 & 1 & 66,5 \\
\hline Lhasa Apso (3) & 5 & 3 & - & 2 & 1 & 108 \\
\hline Poodle (3) & 5 & 4 & 1 & 1 & 2 & 124 \\
\hline Shih Tzu (24) & 34 & 31 & 2 & 14 & 10 & 30,46 \\
\hline SRD (19) & 27 & 26 & 2 & 10 & 9 & 56,43 \\
\hline York Shire (5) & 7 & 6 & 1 & 1 & 4 & 76,5 \\
\hline
\end{tabular}

Quadro 2. Número de bactérias isoladas em 104 olhos com diferentes tipos de ceratites ulcerativas (2012- 2015)

\begin{tabular}{|c|c|c|c|c|c|}
\hline \multirow{4}{*}{ Bactérias } & \multicolumn{5}{|c|}{ Ceratites ulcerativas } \\
\hline & \multirow{3}{*}{$\begin{array}{l}\begin{array}{l}\text { Não complicada } \\
\text { (nº de olhos) }\end{array} \\
\text { Superficial (81) }\end{array}$} & \multicolumn{4}{|c|}{ Complicadas ( $\mathrm{n}^{\circ}$ de olhos) } \\
\hline & & \multirow{2}{*}{ Profunda(8) } & \multirow{2}{*}{ Indolente (2) } & \multirow{2}{*}{ Descemetocele (6) } & Perfuração Corneal \\
\hline & & & & & $(7)$ \\
\hline Bacillus sp. & 5 & 3 & 2 & - & 2 \\
\hline Branhomella sp. & 1 & - & - & - & - \\
\hline Citrobacter sp. & 1 & - & - & - & - \\
\hline Enterobacter sp. & 6 & 4 & - & - & 2 \\
\hline E. coli & 2 & 4 & - & - & 1 \\
\hline Pasteurella canis & 1 & - & - & - & - \\
\hline Proteus mirabilis & 2 & - & - & - & - \\
\hline P. aeruginosa & 10 & 7 & - & 2 & 2 \\
\hline Shigella sp. & 1 & - & - & - & - \\
\hline Staphylococcus sp. & 54 & 4 & 2 & - & 3 \\
\hline Streptococcus sp. & 4 & 3 & 1 & - & 1 \\
\hline Cultura Negativa & 4 & - & - & 3 & 1 \\
\hline
\end{tabular}

P. aeruginosa $=$ Pseudomonas aeruginosa, E. coli $=$ Escherichia coli. 
significativamente maior nos olhos com ceratites ulcerativas não complicadas que naquelas com ceratites ulcerativas complicadas ( $\mathrm{p}=0,011)$ (Fig.2).

o Staphylococcus foi a bactéria mais encontrada nas ceratites ulcerativas não complicadas (54/81; 66,66\%), seguido por P. aeruginosa (10/81; 12,34\%), Enterobacter $(6 / 81 ; 7,40 \%)$, Bacillus (5/81\%; 6,17\%), Streptococcus (4/81; 4,93\%) e pelo Proteus mirabilis e Escherichia coli (2/81; 2,46\%) (Quadro 2). Branhomella, Citrobacter, Pasteurella canis e Shigella foram isoladas em apenas um caso, isoladamente, representando apenas $1,23 \%$ de todos os agentes cultivados em ceratites ulcerativas não complicadas (Quadro 2).

Já nos 23 olhos acometidos por ceratites ulcerativas complicadas, a bactéria mais presente foi P. aeruginosa (11/23; 47,82\%), seguida por Staphylococcus (9/23; 39,13\%),

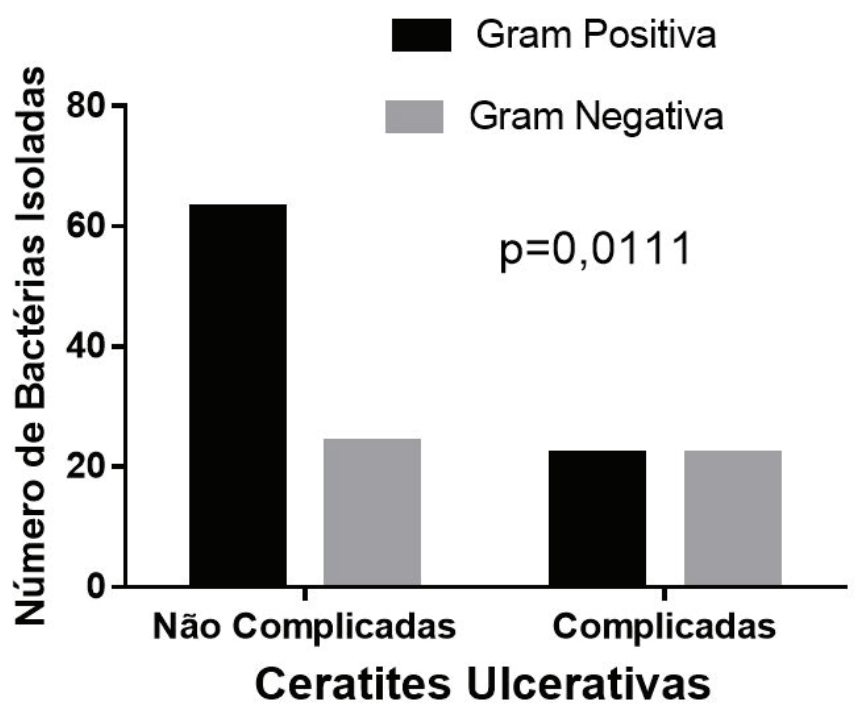

Fig.2. Comparação entre o número de bactérias gram-positivas e gram-negativas isoladas em de cães com ceratites ulcerativas com e sem complicação.
Bacillus (8/23; 34,78\%), Enterobacter $(6 / 23 ; 26,08 \%)$, Streptococcus e de E. coli $(5 / 23 ; 21,73 \%)$ (Quadro 2). As demais bactérias (Branhomella, Citrobacter, Pasteurella canis e o Proteus mirabilis) não foram isoladas em ceratites ulcerativas complicadas (Quadro 2).

Dos 8 antibióticos testados, o ofloxacino foi o mais eficiente nos diferentes isolados $(84,55 \%)$, seguido da gentamicina $(71,97 \%)$ e da tobramicina $(68,24 \%)$. A neomicina foi o antibiótico que apresentou pior eficiência (23,42\%) (Quadro 3). 0 ofloxacino apresentou eficácia significativamente maior $(\mathrm{p}<0,0001)$ que a neomicina, a polimixina $\mathrm{B}$, o cloranfenicol, a moxifloxacina, a tobramicina ( $\mathrm{p}=0,0007)$, o ciprofloxacino $(p=0,0004)$ e a gentamicina $(p=0,0021)$. Considerando o resultado dos antibiogramas, Streptoccocus sp. foi a bactéria que apresentou maior resistência (53/70; 72,61\%), diferentemente de E. coli, que foi a bactéria mais sensível (46/61; 75,41\%) (Quadro 3).

Das 131 bactérias isoladas, 99 (75,57\%) foram cultivadas de olhos que cicatrizaram apenas com tratamento clínico e, $32(24,42 \%)$ bactérias foram isoladas de olhos que precisaram de tratamento cirúrgico (Quadro 4). Dos olhos manejados clinicamente, 65 bactérias isoladas eram Gram-positivas e 34 eram Gram-negativas. Nos olhos que receberam cirurgia, 20 isolados eram Gram-positivos e 12 eram Gram-negativos. 0 número de bactérias Gram-positivas foi maior que o de Gram-negativas, tanto nos casos tratados com tratamento médico, como nos que foram operados, sem significativa estatística $(\mathrm{p}=0,745)$.

Relativamente ao número de bactérias isoladas nos olhos tratados apenas clinicamente, observou-se predomínio do gênero Staphylococcus (54/99; 54,54\%), seguido por Pseudomonas aeruginosa $(15 / 99 ; 15,15 \%)$, Enterobacter (8/99; 8,08\%), Streptococcus (6/99; 6,06\%), Bacillus e Escherichia coli (5/99; 5,05\%) (Quadro 4). Das 32 bactérias isoladas de olhos que demandaram cirurgia, o gênero mais comumente isolado foi Staphylococcus (9/32; 28,12\%), seguido por Bacillus $(8 / 32 ; 25 \%)$, Pseudomonas aeruginosa $(6 / 32 ; 18,75 \%)$, Enterobacter $(4 / 32 ; 12,50 \%)$, Streptococcus $(3 / 32 ; 9,37 \%)$ e E. coli $(2 / 32 ; 6,25 \%)$ (Quadro 4).

Quadro 3. Resultado do teste de susceptibilidade antibacteriana aos isolados Staphylococcus sp., Pseudomonas aeruginosa (P. aeruginosa), Streptococcus sp., Enterobacter sp., Bacillus sp. e a Escherichia coli (E. coli), em diferentes tipos de ceratites ulcerativas em cães (2012-2015)

\begin{tabular}{|c|c|c|c|c|c|c|c|c|c|c|c|c|}
\hline & \multicolumn{2}{|c|}{ Staphylococcus } & \multicolumn{2}{|c|}{ Streptococcus } & \multicolumn{2}{|c|}{ P. aeruginosa } & \multicolumn{2}{|c|}{ Bacillus } & \multicolumn{2}{|c|}{ Enterobacter } & \multicolumn{2}{|c|}{ E. coli } \\
\hline & $\mathrm{S}$ & $\mathrm{R}$ & $\mathrm{S}$ & $\mathrm{R}$ & $\mathrm{S}$ & $\mathrm{R}$ & $\mathrm{S}$ & $\mathrm{R}$ & $\mathrm{S}$ & $\mathrm{R}$ & $S$ & $\mathrm{R}$ \\
\hline Ofloxacino & 48 & 12 & 5 & 4 & 16 & 3 & 10 & - & 12 & - & 7 & 1 \\
\hline Ciprofloxacino & 42 & 20 & 1 & 8 & 13 & 7 & 8 & 1 & 10 & 2 & 6 & 1 \\
\hline Moxifloxacina & 38 & 13 & 3 & 6 & 6 & 11 & 6 & 4 & 6 & 6 & 5 & 3 \\
\hline Tobramicina & 41 & 19 & 1 & 8 & 16 & 4 & 8 & 2 & 7 & 3 & 6 & - \\
\hline Gentamicina & 43 & 19 & 1 & 8 & 13 & 5 & 10 & - & 11 & 1 & 7 & 1 \\
\hline Neomicina & 31 & 29 & - & 9 & 5 & 14 & 5 & 5 & - & 11 & 1 & 7 \\
\hline Cloranfenicol & 39 & 17 & 6 & 3 & 1 & 19 & 6 & 2 & 8 & 2 & 7 & 1 \\
\hline Polimixina B & 24 & 24 & - & 7 & 10 & 7 & 2 & 6 & 7 & 1 & 7 & 1 \\
\hline Total & 306 & 44 & 17 & 53 & 80 & 70 & 55 & 20 & 61 & 26 & 46 & 15 \\
\hline
\end{tabular}

* $\mathrm{S}=$ sensível, $\mathrm{R}$ = resistente. 
Quadro 4. Número de bactérias isoladas relativamente ao tipo de tratamento adotado, em diferentes tipos de ceratites ulcerativas em cães (2012-2015)

\begin{tabular}{ccc}
\hline Bactérias & Tratamento clínico & Tratamento cirúrgico \\
\hline Bacilluss $\mathrm{p}$. & 5 & 8 \\
Branhomella sp. & 1 & - \\
Citrobacter $\mathrm{sp}$. & 1 & - \\
Enterobacter $\mathrm{sp}$. & 8 & 4 \\
Escherichia coli & 5 & 2 \\
Pasteurella canis & 1 & - \\
Proteus mirabilis & 2 & - \\
Pseudomonas aeruginosa & 15 & 6 \\
Shigella sp. & 1 & - \\
Staphylococcus sp. & 54 & 9 \\
Streptococcus sp. & 6 & 3 \\
Cultura Negativa & 4 & 4
\end{tabular}

\section{DISCUSSÃO}

O presente estudo apresenta resultados de suma importância para a escolha de antibióticos em diferentes tipos de ceratites ulcerativas em cães na região Centro Oeste do Brasil. À similitude do que fora reportado por Tolar et al. (2006) e Hindley et al. (2016), em nossa pesquisa, as raças braquicefálicas (Shih Tzu e Lhasa Apso) foram mais acometidas $(30,66 \%)$, comparativamente as demais raças. A maior incidência de raças braquicefálicas observadas na presente pesquisa pode ser atribuída a conformação da órbita mais rasa e a maior predisposição à anormalidades dos anexos oftálmicos como triquíase da carúncula, triquíase da prega nasal e distiquíase, afecções que comumente são encontradas em tais raças (Gelatt \& Brooks 2011).

Mesmo selecionando pacientes sem tratamento prévio com antibióticos tópicos ou sistêmicos, observou-se que $8 / 104(7,69 \%)$ olhos aqui estudados apresentaram cultura negativa. Outro estudo realizado na Austrália, que considerou incluir na pesquisa pacientes com ceratites ulcerativas que possuíam tratamento prévio com antibióticos, relatou-se que a taxa de culturas negativas foi de $41 \%$, bem mais elevada que em nosso estudo (Hindley et al. 2016). Em outro experimento realizado em Taiwan, Lin \& Petersen-Jones (2007) relataram que culturas positivas foram isoladas em 190/268 (71\%) dos olhos ulcerados, sendo que as amostras foram colhidas diretamente dos bordos ulcerados. Porém, os pesquisadores não deixaram claro se os cães estavam recebendo tratamento prévio com antibióticos (Lin \& Petersen-Jones 2007). No Ceará, os pesquisadores reportaram que em 21 dos olhos acometidos por ceratite ulcerativa, em $100 \%$ dos casos foi possível se cultivar algum tipo de bactéria, pois as amostras foram colhidas do saco conjuntival, antes do teste de tingimento com fluoresceína e da lavagem do excesso de corante. Em nosso estudo, as culturas negativas representaram apenas 7,69\% dos olhos avaliados e que tal fato não deva ser atribuído à lavagem do olho para a remoção de fluoresceína, procedimento esse, realizado previamente à realização do swab para colheita das amostras. Ademais, foi constatado na anamnese que os pacientes incluídos na pesquisa não estavam sendo tratados previamente com nenhuma substância ocular. A literatura veterinária relata que culturas provenientes de swab do saco conjuntival podem ser negativas em 6\% dos cães com olhos sadios (Hamor 2001).

Igualmente ao que fora relatado previamente em outro estudo realizado no Brasil, observou-se que Staphylococcus sp. foi a bactéria mais prevalente em cães com ceratite ulcerativa (Prado et al. 2005) e naqueles com diferentes oftalmopatias (Santos et al. 2009). Staphylococcus sp. também foi o gênero mais comumente isolado em cães com ceratite ulcerativa nos Estados Unidos (Tolar et al. 2006), na China (Lin \& Petersen-Jones 2007) e em Taiwan (Wang et al. 2008). A maior prevalência desse agente, relativamente ao seu isolamento de córneas ulceradas se justifica pelo fato de que o gênero é o mais comumente encontrado em olhos de cães sadios no Brasil (Andrade et al. 2002, Prado et al. 2005) e em outras localidades do mundo (Hamor 2001). Tal fato confirma que o agente desempenha papel importante na defesa do hospedeiro, interferindo com a colonização de organismos oportunistas (Wang et al. 2008)

Já na Austrália, Streptococcus $\beta$-hemolítico foi a bactéria mais prevalente, compreendendo 31\% dos isolados encontrados em cães acometidos por diferentes tipos de ceratites ulcerativas (Hindley et al. 2016). Tal observação contrasta com os achados de nossa pesquisa e daquelas previamente reportadas, salientando a importância de estudos dessa natureza devam ser repetidos ao longo dos anos e em diferentes regiões do mundo. Observou-se em nosso estudo que houve predomínio significativo de bactérias gram-positivas frente às gram-negativas. Todavia, nos Shih Tzus, o número de isolados gram-negativos foi significativamente maior que nas raças Pinscher, Fila, Poodle e os sem raça definida. Em estudo prévio conduzido na mesma instituição, Santos et al. (2009) estudou a microbiota ocular de cães sadios e com oftalmopatias diversas. Os autores constataram que apenas 1/100 cães avaliados eram da raça Shih Tzu, impossibilitando maiores comparações com os resultados obtidos na presente pesquisa. Dessa forma, ressalta-se a importância de que estudos dessa natureza devam sejam repetidos ao longo dos anos na mesma localidade.

Admite-se que Pseudomonas aerugenosa possui elevado potencial em produzir metaloproteinases que podem prolongar a digestão do colágeno corneal por até 12 horas, decorrido o início com tratamento antibiótico, o que geralmente enseja perfuração corneal e perda do bulbo ocular (Ikema et al. 2006). Na presente pesquisa, observou-se que dos 23 olhos acometidos por ceratites complicadas por digestão do estroma corneal, que $P$. aeruginosa foi encontrada em $47,82 \%$ dos casos (11/23). Já nos olhos com ceratites ulcerativas sem complicação, P. aeruginosa foi o segundo agente mais encontrado, compreendendo 12,34\% (10/81) dos agentes isolados. Ressalva-se que apenas 28,57\% (6/21) das P. aeruginosa isoladas nos olhos com ceratite ulcerativa fizeram com que tais olhos necessitassem da correção cirúrgica, diferindo dos achados de Hindley et al. (2016), onde 62\% (5/8) dos olhos em que essa bactéria foi isolada precisaram ser submetidos a cirurgia. Nos demais casos de onde foi isolada essa bactéria (15/21, 71,42\%), apenas instilações de antibióticos a base de tobramicina ou cloranfenicol, aliados ao tratamento anti-colagenolítico com EDTA e soro sanguíneo foram suficientes para conter a infeção e a autodigestão do estroma corneal. 0 percentual de casos acometidos por P. aeruginosa que necessitaram de cirurgia pode ser justificado pelo fato 
que algumas cepas apresentam potencial citotóxico, ao passo que outras um potencial mais invasivo (Ledbetter et al. 2009). Sabe-se que o potencial citotóxico é mais expressivo em cães jovens acometidos por ceratite ulcerativa, que em cães idosos, onde o sistema imune é mais deficitário, permitindo maior invasão estromal pelo agente (Ledbetter et al. 2009). No presente estudo, não se considerou correlacionar a idade com a deterioração da ceratite ulcerativa. Todavia, admite-se que nos 15/21 casos onde $P$. aeruginosa foi isolada e houve resolução com tratamento tópico possa ser devido ao que fora reportado por outros autores (Ledbetter et al. 2009).

Embora P. aueruginosa e outras bactérias possuam potencial de produzir MMPs, na presente pesquisa, das 8 úlceras que apresentaram cultura negativa, 50\% necessitaram de tratamento cirúrgico. Desse contingente, três apresentaram decementocele e outro, uma perfuração corneal. Tal fato demonstra que a deterioração do estroma corneal por essas enzimas pode ocorrer mesmo na ausência de bactérias, sugerindo que tratamento agressivo contra MMPs deva ser instituído mesmo em úlceras superficiais.

Embora nas ceratites ulcerativas indolentes a doença sempre acometer a camada epitelial da córnea, permanecendo a membrana basal intacta, resolvemos agrupar essa afecção nas ceratites complicadas, pois sempre precisam de cirurgia para sua resolução completa (Gelatt \& Brooks 2011). Desconhecem-se publicações sobre o impacto de diferentes bactérias nesse tipo de ceratite ulcerativa em oftalmologia veterinária. Na presente pesquisa, apenas dois casos foram incluídos e ambos apresentaram cultura mista (Bacillus sp., Staphylococcus sp. e Streptococcus sp.). Em ambos os casos houve resolução completa do quadro após cirurgia e tratamento com tobramicina, mesmo diante da alta resistência de Streptococcus sp. à esse antibiótico. Admite-se que a permanência da membrana basal e da baixa elevação no quantitativo de MMP-2 e -9 nesse tipo de ceratopatia podem sugerir que o contingente bacteriano possa não ter tanta importância na evolução da úlcera (Carter et al. 2007). Todavia, observações provenientes de outras pesquisas devem ser avaliadas para certificar dessa afirmativa.

Dos 8 antibióticos aqui testados, o ofloxacino foi o mais eficiente nos diferentes isolados (84,55\%), seguido da gentamicina $(71,97 \%)$ e da tobramicina $(68,24 \%)$. Em um estudo que avaliou a susceptibilidade de $P$. aeruginosa em 27 cães com ceratites ulcerativa, demonstrou que os isolados desse gênero eram sensíveis a fluoroquinolonas de primeira, segunda, terceira e quarta geração (Ledbetter et al. 2007). Na Austrália e na Inglaterra, cães com ceratite ulcerativa, o gênero Pseudomonas também foi sensível ao ciprofloxacino e ao ofloxacino (Hindley et al. 2016, Everson et al. 2016). Em isolados de humanos com ceratite ulcerativa, demonstrou-se que fluorquinolonas de quarta geração apresentam menos resistência que as de primeira e segunda gerações (Kowalski et al. 2003). Na nossa pesquisa, a maioria dos agentes gram-positivos e gram-negativos foram sensíveis as fluorquinolonas, ofloxacino e ciprofloxacino (fluorquinolonas de segunda geração), mas apresentaram sensibilidade significativamente menor à moxifloxacina (quarta geração). 0 fato de uma fluorquinolona de quarta geração, que não fazia parte de nossa primeira escolha de tratamento para ceratite ulcerativa ou de qualquer outra afecção ocular apresentar resistência frente a uma fluroquinolona de segunda geração, pode ser justificado. Admite-se ser possível que a resistência frente a moxifloxacina seja proveniente do fato que o agente é amplamente utilizado por veterinários da mesma instituição para tratamento de otites externas de origem bacteriana há mais de 5 anos. A menor eficácia da neomicina e da polimixina $\mathrm{B}$, sobre os agentes isolados em nossa pesquisa, corroboram com os achados descritos em outras pesquisas realizadas com antibióticos encontrados em compostos específicos, utilizados topicamente para o tratamento de infecções oculares (Tolar et al. 2006, Hindley et al. 2016).

Embora Streptococcus sp. tenha sido um dos agentes menos isolados em olhos que receberam apenas tratamento clínico $(6,06 \%)$ e cirúrgico $(9,37 \%)$, esse agente foi o que apresentou maior resistência aos 8 antibióticos testados em nosso estudo. Em nossa pesquisa, o cloranfenicol e o ofloxacino foram os agentes mais eficazes contra esse agente, similar ao que foi reportado em cães acometidos por ceratites ulcerativas em outras regiões do mundo (Tolar et al. 2006, Lin \& Petersen-Jones 2007, Hindley et al. 2016). Mesmo considerando que a tobramicina e a gentamicina, foram o segundo e o terceiro antibiótico mais eficiente contra a maior parte dos isolados na presente pesquisa, deve-se ter cautela com a interpretação desse resultado, haja vista que dos 9 Streptococcus aqui isolados, apenas $1 / 9$ foi sensível à tobramicina e a gentamicina. Dessa forma, admite-se que cloranfenicol e ofloxacino sejam os agentes de primeira escolha quando se isolam Streptococcus em ceratites ulcerativas de cães da nossa região.

\section{CONCLUSÕES}

O estudo demonstrou que Staphylococcus sp. foi o organismo mais comumente isolado nos diferentes casos de ceratites ulcerativas.

Em nossa região, embora Pseudomonas aeruginosa tenha sido isolada em $47,82 \%$ dos olhos com ceratites complicadas, na maior parte dos olhos, o tratamento clínico foi suficiente para cura da afecção corneal.

Ofloxacino e gentamicina foram os agentes mais eficazes contra a maioria dos isolados, com a exceção de Streptococcus sp., onde o cloranfenicol se mostrou o mais eficaz.

Ceratites ulcerativas sem complicações que apresentem culturas negativas podem evoluir para ceratites ulcerativas complicadas, salientando a necessidade de tratamento anti-colagenolítico adjunto em todos os casos.

\section{REFERÊNCIAS}

Andrade A.L., Stringhini G., Bonello F.L., Marinho M. \& Perri S.H.V. 2002. Microbiota conjuntival de cães sadios da cidade de Araçatuba, SP. Arq. Bras. Oftalmol. 65(3):323-326. http://dx.doi.org/10.1590/S000427492002000300008 .

Carter R.T., Kambampati R., Murphy C.J. \& Bentley E. 2007. Expression of Matrix Metalloproteinase 2 and 9 in experimentally wounded canine corneas and spontaneous chronic corneal epithelial defects cornea. Cornea 26(10):1213-1219. http://dx.doi.org/10.1097/IC0.0b013e31814b8a28. PMid:18043179.

Everson R.M., Koll S. \& Sanchez R.F. 2016. Corneal cytology and bacterial isolates from stromal ulcers in 26 dogs: antimicrobial sensitivities and treatment outcomes. Proceedings of the Annual Scientific Meeting of the European College of Veterinary Ophthalmologists, Budapest, p.6. 
Galera P.D., Laus J.L. \& Oriá A.P. 2009. Afecções da túnica fibrosa, p.69-92 In: Laus J.L. (Ed.), Oftalmologia Clínica e Cirúrgica em Cães e em Gatos. Roca, São Paulo.

Gelatt K.N. \& Brooks D. 2011. Surgery of the cornea and sclera, p.191-235. In: Gelatt K.N. \& Gelatt J.P. (Eds), Veterinary Ophthalmic Surgery. Saunders Elsevier, Gainesville. http://dx.doi.org/10.1016/B978-0-7020-34299.00008-0.

Hamor R.E. 2001. Techniques for collection and interpretation of tissue samples in ocular disease. Clin. Tech. Small Anim. Pract. 16(1):17-21. http://dx.doi.org/10.1053/svms.2001.22800. PMid:11373825.

Hendrix D.V., Ward D.A. \& Barnhill M.A. 2001. Effects of antibiotics on morphologic characteristics and migration of canine corneal epithelial cells in tissue culture. Am. J. Vet. Res. 62(10):1664-1669. http://dx.doi. org/10.2460/ajvr.2001.62.1664. PMid:11592337.

Hindley K.E., Groth A.D., King M., Graham K. \& Billson M. 2016. Bacterial isolates, antimicrobial susceptibility, and clinical characteristics of bacterial keratitis in dogs presenting to referral practice in Australia. Vet. Ophthalmol. 19(5):418-426. http://dx.doi.org/10.1111/vop.12325. PMid:26522379.

Ikema K., Matsumoto K., Inomata Y., Komohara Y., Miyajima S., Takeya M. \& Tanihara H. 2006. Induction of matrix metalloproteinases (MMPs) and tissue inhibitors of MMPs correlates with outcome of acute experimental pseudomonal keratitis. Exp. Eye Res. 83(6):1396-1404. http://dx.doi. org/10.1016/j.exer.2006.07.019. PMid:16968651.

Kowalski R.P., Dhaliwal D.K., Karenchak L.M., Romanowski E.G., Mah F.S., Ritterband D.C. \& Gordon Y.J. 2003. Gatifloxacin and Moxifloxacin: an in vitro susceptibility comparison to levofloxacin, ciprofloxacin, and ofloxacin using bacterial keratitis isolates. Am. J. Ophthalmol. 136(3):500-505. http://dx.doi.org/10.1016/S0002-9394(03)00294-0. PMid:12967804.

Lalitha P., Prajna V.N., Srinivasan M. \& Smitha S. 2005. Susceptibility trends of Pseudomonas species from corneal ulcers. Indian J. Med. Microbiol. 23(3):168-171. http://dx.doi.org/10.4103/0255-0857.16588. PMid:16100422.

Ledbetter E.C., Hendricks L.M., Riis R.C. \& Scarlett J.M. 2007. In vitro fluoroquinolone susceptibility of Pseudomonas aeruginosa isolates from dogs with ulcerative keratitis. Am. J. Vet. Res. 68(6):638-642.http://dx.doi. org/10.2460/ajvr.68.6.638. PMid:17542697.

Ledbetter E.C., Mun J.J., Kowbel D. \& Fleiszig S.M. 2009. Pathogenic phenotype and genotype of pseudomonas aeruginosa isolates from spontaneous canine. Invest. Ophthalmol. Vis. Sci. 50(2):729-736. http://dx.doi.org/10.1167/ iovs.08-2358. PMid:18836164.

Lin C.-T. \& Petersen-Jones S.M. 2007. Antibiotic susceptibility of bacterial isolates from corneal ulcers of dogs in Taiwan. J. Small Anim. Pract. 48(5):271-274. http://dx.doi.org/10.1111/j.1748-5827.2007.00348.x. PMid:17425695.

Prado M.R., Rocha M.F.G., Brito E.H.S., Girão M.D., Monteiro A.J., Teixeira M.F.S. \& Sidrim J.J.C. 2005. Survey of bacterial microorganisms in the conjunctival sac of clinically normal dogs and dogs with ulcerative keratitis in Fortaleza, Ceará, Brazil. Vet. Ophthalmol. 8(1):33-37. http://dx.doi. org/10.1111/j.1463-5224.2005.04061.x. PMid:15644098.

Quinn P.J., Carter M.E. \& Markey B. 1994 Clinical Veterinary Microbiology. Vol.1. Wolfe Publishing, London, p.17-66.

Ribeiro A.P. 2015. Oftalmologia, p.683-722. In: Crivellenti Z. \& Borin-Crivellenti S. (Eds), Casos de Rotina em Medicina Veterinária de Pequenos Animais. $2^{\underline{a}}$ ed. MedVet, São Paulo.

Santos L.G.F., Almeida A.B.P.F., Silva M.C.S., Oliveira J.T., Dutra V. \& Souza V.R.F. 2009. Microbiota conjuntival de cães hígidos e com afecções oftálmicas. Acta Scient. Vet. 37:165-169.

Tolar E.L., Hendrix D.V., Rohrbach B.W., Plummer C.E., Brooks D.E. \& Gelatt K.N. 2006. Evaluation of clinical characteristics and bacterial isolates in dogs with bacterial keratitis: 97 cases (1993-2003). J. Am. Vet. Med. Assoc. 228(1):80-85. http://dx.doi.org/10.2460/javma.228.1.80. PMid:16426172.

Wang L., Pan Q., Zhang L., Xue Q., Cui J. \& Qi C. 2008. Investigation of bacterial microorganisms in the conjunctival sac of clinically normal dogs and dogs with ulcerative keratitis in Beijing, China. Vet. Ophthalmol.11(3):145-149. http://dx.doi.org/10.1111/j.1463-5224.2008.00579.x. PMid:18435654. 